\title{
The validation of a diversity climate measurement instrument for the South African environment
}

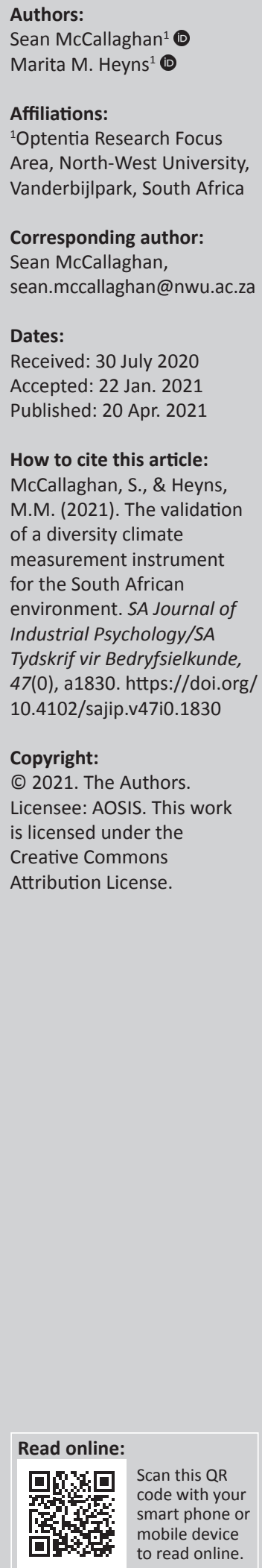

Orientation: South Africa had a distinctive diversity environment with unique diversity-related challenges. Researchers and practitioners required a validated diversity climate instrument that can be used to examine diversity management observations in a South African setting.

Research purpose: The objective of this study was to address a research opportunity to source, test and validate a diversity climate instrument for the South African environment.

Motivation for the study: Studies examining the conceptualisation, validation and measurement invariance of a diversity climate instrument for the South African environment do not yet exist.

Research approach/design and method: A quantitative approach with cross-sectional design was utilised. A total of 323 respondents from a convenience sample formed part of this study. Statistical analysis included reliability, validity and measurement invariance computations.

Main findings: An applicable one-dimensional diversity climate assessment instrument was identified from literature. This study found evidence indicating that the instrument was reliable and valid across white and African population groups.

Practical/managerial implications: The assessment of diversity climate will be an accurate indication on how well an organisation is managing diversity. A validated measuring instrument will be a valuable managerial tool for any South African organisation, which can assist with future decision making.

Contribution/value-add: This study was able to source and validate a diversity climate measuring instrument for a unique diversity setting, such as South Africa.

Keywords: diversity climate; diversity management; validation; measurement invariance; South Africa.

\section{Introduction}

\section{Background and orientation for the study}

South Africa is considered as an intriguing environment for studying diversity, yet there is no validated instrument available to assess diversity climate. This is due especially to South Africa's history of legalised segregation and recent legislative attempts to improve diversity (Jackson \& Van de Vijver, 2018). An emerging area within the diversity management domain is on how employees form opinions with regard to diversity - also known as diversity climate. Diversity climate is especially important for organisations, as this concept within the diversity management domain is associated with several diversity-related benefits (Cachat-Rosset, Carillo, \& Klarsfeld, 2019).

Several mainstream definitions of diversity climate exist in the current literature. McKay et al. (2007) proposed that diversity climate should be considered as the shared employee perception of how committed the organisation is towards diversity regarding fair human resource policies and practices. According to Pugh, Dietz, Brief and Wiley (2008), diversity climate can be considered as the shared employee perceptions of the policies and practices, indicating to what extent the organisation is committed to eliminating discrimination and to valuing diversity. In addition, McKay, Avery and Morris (2008, p. 352) considered diversity climate as the 'degree to which a firm advocates fair human resource policies and socially integrates under-represented employees'. McKay et al. (2008, p. 352) further explained that 'diversity climate entails how social context is affected by group membership, as manifested in various forms of demographic differences'. According to Hofhuis, Van der Zee and Otten (2012, p. 969), a diversity climate can be considered as 'the degree to which an organisational climate facilitates the presence of cultural differences, and views this diversity as a positive asset'. 
Whilst all these conceptual views remain applicable in the diversity climate literature, recent reviews have identified several conceptual challenges, including limitations of validations for diversity climate measurements (CachatRosset et al., 2019; McKay \& Avery, 2015). Therefore, the aim of this study was to examine and formulate a conceptual view of diversity climate for the South African environment and to also source and examine the psychometric properties of a diversity climate measuring instrument.

\section{Research purpose}

The primary objective was based on research opportunities identified through literature review. These opportunities stem from a lack of validations and accurate conceptualisations of diversity climate assessments (Cachat-Rosset et al., 2019; McKay \& Avery, 2015) and concern about measurement invariances identified by South African researchers when examining psychometric properties of international measuring instruments (Steyn \& De Bruin, 2020) and South Africa's distinctive diversity management environment.

In their landmark article, McKay and Avery (2015) identified several critical areas of diversity climate that required attention. One of the areas the authors identified was challenges with regard to the conceptualisation and construct validation of diversity climate assessments. Researchers have also identified several challenges associated with multidimensional measures of diversity climate, with some of the measures overlapping with assessments of inclusion climate and psychological diversity climate (individual level) rather than an aggregate (organisational level) (Holmes et al., 2020). In order to mitigate this risk, the present study focussed on a one-dimensional measurement aligned with organisational diversity climate view from McKay et al. (2007). Consequently, the primary aim of the present study is to validate a one-dimensional diversity climate assessment in a South African environment.

According to Steyn and De Bruin (2020), it is imperative to validate instruments, especially when the aim is to conduct cross-comparisons between groups in South African environments. This is also applicable to the validation of a diversity climate assessment, especially taking into account that diversity climate assessments were initially conceptualised to examine subcultures (Mor Barak, Cherin, \& Berkman, 1998). However, the concern is that recent South African examinations struggled to validate certain instruments. For example, Steyn and De Bruin (2020) could not validate the assessment of individual proactiveness, the nine-item Utrecht Work Engagement Scale (UWES-9) and an Organisational Commitment Scale in order to compare gender groups. Similarly, Heyns and Ellis (2013) could also not validate a trustworthiness assessment aimed at comparing trustworthiness observations between ethnic groups. Whilst several South African authors have successfully validated several Western-based measurements, it would seem that in certain situations, this remains a challenge.
South Africa has a demanding and challenging diversity management environment. The rationale underlying the management of differences within organisations is based on the advantages associated with managing diversity effectively. The management of diversity also necessitates that organisational leaders should take a certain standpoint on diversity. Employees formulate perspectives on these stances, which in turn form a diversity climate (Mckay \& Avery, 2015). Therefore, the management of diversity within organisations must be reflected in an assessment of diversity climate.

In terms of the South African scenario, legislation that promotes the South African diversification process is unique and it may, therefore, be argued that the South African diversity management landscape is also distinctive. A typical example of why our diversified management environment is unlike other areas in the world is our reference to majorities and minorities. From a Western perspective, minorities are mainly considered to be black people, African people and people of mixed race, whilst in the South African context, African, mixed race and Indian people are considered as the majority, with white people being the minority. To further illustrate how unique South Africa's diversity management landscape is, our labour market is still dominated by one South African minority, namely, white people (Statistics South Africa, 2020). It is these unique diversity management features that make South Africa's diversity environment unique and warrant the validation of Western measurements before they can be used in a South African environment.

\section{Literature review Diversity climate: A brief overview}

The concept, diversity climate, was initially proposed when Cox (1993) developed the Interactional Model for Cultural Diversity (IMCD). The foundation of the IMCD was that diversity interactions took place at an individual and organisational level and these interactions then affected individual employee behaviour and organisational performance. Subsequently, diversity climate literature evolved and was then viewed from an individual and organisational perspective with the development of the diversity perception scale (DPS) developed by Michál E. Mor Barak et al. (1998). According to Mor Barak et al. (1998), diversity climate can be viewed from a perspective of organisational fairness and inclusion (organisational level) and personal diversity value and personal comfort (individual level). However, the latter view of diversity climate has been criticised by authors because of similarities with psychological diversity climate (Holmes et al., 2020) and difficulty in validating the DPS in non-US samples (Paolillo, Pasini, Silva, \& Magnano, 2017) and has therefore not considered as conceptual framework for the present study.

After the initial development of diversity climate as a concept within the diversity management domain, scholars turned 
their focus to the consequences of diversity climate. These examinations found evidence that diversity climate had an impact on employee attitudes, individual performance and unit-level outcomes, for example, productivity and sale performances (Holmes et al., 2020; Mckay \& Avery, 2015).

Historically, diversity climates were assessed to evaluate any possible sub-climates (Mckay \& Avery, 2015; Mor Barak et al., 1998). The views of subcultures were mainly based on the framework provided by social identity theory (SIT; Tafjel \& Turner, 1986). Social identity theory proposes that individuals form groups based on their similarities, for example, race, religion and language. Based on SIT, diversity climate scholars further proposed that employees formed subgroups based on gender and race and these subgroups then formed their own diversity-related opinions (Mor Barak et al., 1998). The challenge for organisations is that subclimates hold several organisational disadvantages, especially if those subclimates are based on race (Leslie, 2017). Disadvantages may include higher absenteeism, employee turnover and more divergent behaviour (Jackson et al., 1991). A majority of subclimate examinations focused on gender perspectives (Holmes et al., 2020) and therefore, the current examination has the opportunity to contribute towards diversity climate knowledge with a study dedicated to the validation across race groups.

As a result of South Africa's unfortunate history of segregation and economic exclusion of certain ethnic groups, we view the validation of a diversity climate assessment instrument in order to compare diversity climate observations across demographical groups as an important contribution towards diversity management and diversity climate literature.

\section{Diversity climate for the modern organisation}

Diversity climate holds several organisational and individual benefits for maintaining a persistently conducive diversity climate (Cox, 1994; Holmes et al., 2020; Mckay \& Avery, 2015). Although diversity climates are assessed based on individual perceptions of diversity, recent studies found that diversity climate could have a significant impact on organisational performance especially when employees from different demographic backgrounds agreed that a diversity climate was conducive (Reinwald, Huettermann, \& Bruch, 2019).

From a service perspective, findings from the hospitality and tourism sector indicate that a conducive diversity climate can also result in improved innovative service behaviour. Furthermore, diversity climate is also associated with harmonious passion for work (Luu, 2019). From a South African perspective, positive opinions of diversity climate have been associated with job satisfaction, organisational commitment and reduced observations of turnover intentions (McCallaghan, Jackson, \& Heyns, 2019).

\section{Diversity climate and the South African context}

South African organisations have unique diversity-related challenges because of South Africa's unique history of segregation. For example, the South African labour force remains dominated by certain population groups (Statistics South Africa, 2020). In order to address historic labour imbalances and economic disparities, the democratically elected South African parliament developed and implemented a world-renowned constitution (1996) aimed at eradicating unfair discrimination and creating a free society where all individuals irrespective of different backgrounds can live and work together harmoniously.

South Africa has also developed a unique set of legislative frameworks to fast track corrective diversification and correct historically created economic disparities. These legislative frameworks include, but are not limited to, the Constitution (1996), Labour Relations Act 66 of 1995, Basic Conditions of Employment Act 75 of 1997, Employment Equity Act 55 of 1998 and the Broad-Based African Economic Empowerment Act 53 of 2003. In summary, South Africa is striving to build a workforce that reflects the South African demographic composition whilst also stimulating a value for diversity amongst citizens and employees.

Legislation that governs diversity is seen as an important foundation for diversity management interventions (Peterson, 1999). Consequently, a South African conceptualisation of diversity climate should encapsulate the specific South African dynamics and central diversity-related themes. These themes include: (1) appreciation of diversity (appreciation), (2) wellformulated diversity-related policies and procedures (diversity guidelines) and (3) a stimulated process of diversification in order to improve representation of under-represented labour and economic groups (diversification).

Taking into consideration the preceding paragraphs, the present study considers diversity climate in the South African environment as a representation of employee perceptions on how well the organisation is able to create openness and an appreciation of diversity through its formulated diversity management-related policies, practices and procedures, including the stimulation of a diversification process. It is against this backdrop that South African organisations require a validated measuring instrument that complies with the proposed conceptualisation in order to assess the progress of diversity management interventions from a South African perspective.

A search of the diversity climate literature revealed several measuring instruments (Cachat-Rosset et al., 2019). One such instrument is the (nine-item) one-dimensional diversity climate measurement scale developed by McKay et al. (2007). A closer inspection of the scale reveals that it fits with the conceptual role as proposed in the current study. The scale is depicted in Table 1, which also shows the conceptual diversity climate themes per scale items as proposed in the present study. The DPS developed by Mor Barak et al. (1998) 
TABLE 1: One-dimensional diversity climate measurement scale and proposed conceptual elements.

\begin{tabular}{|c|c|c|}
\hline Number & Items (McKay et al., 2007) & Conceptual elements \\
\hline 1 & Recruiting from diverse sources & Diversification \\
\hline 2 & Offering equal access to training & Diversity guidelines \\
\hline 3 & $\begin{array}{l}\text { Opening communication on } \\
\text { diversity }\end{array}$ & Appreciation \\
\hline 4 & Publicising diversity principles & Appreciation and diversity guidelines \\
\hline 5 & $\begin{array}{l}\text { Offering training to manage } \\
\text { diverse populations }\end{array}$ & $\begin{array}{l}\text { Diversification, diversity guidelines } \\
\text { and diversification }\end{array}$ \\
\hline 6 & $\begin{array}{l}\text { Respecting perspectives of } \\
\text { people like me }\end{array}$ & Appreciation and diversification \\
\hline 7 & $\begin{array}{l}\text { Maintaining a diversity-friendly } \\
\text { work environment }\end{array}$ & Appreciation and diversity guidelines \\
\hline 8 & $\begin{array}{l}\text { Workgroup having climate that } \\
\text { values diverse perspectives }\end{array}$ & Appreciation and diversity guidelines \\
\hline 9 & $\begin{array}{l}\text { Top leaders visibly committed } \\
\text { to diversity }\end{array}$ & Diversification and diversity guidelines \\
\hline
\end{tabular}

Source: Adapted from McKay, P.F., Avery, D.R., Tonidandel, S., Morris, M.A., Hernandez, M., \& Hebl, M.R. (2007). Racial differences in employee retention: Are diversity
climate perceptions the key? Personnel Psychology, 60(1), 35-62. https://doi.org/10.1111/ climate perceptions the key?

was also considered. However, recent validation problems from non-US samples (Paolillo et al., 2017) directed the current study towards the one-dimensional scale from McKay et al. (2007).

\section{Research design Research approach}

The primary objective of this empirical examination was to assess the psychometric properties of the one-dimensional diversity climate measurement instrument developed by McKay et al. (2007) in a South African organisational environment. This study adopted a quantitative approach with a cross-sectional design. Cross-sectional studies have experienced a renewed interest as they provide insightful information at a single point in time (Spector, 2019).

\section{Participants and sampling}

Data were collected from an existing database. In total, 324 responses were collected from a convenience sample. Participants were all based in the Gauteng province of South Africa. Participants were employed in the service sector, manufacturing, industrial and retail sectors. Sample characteristics of the participants are depicted in Table 2.

\section{Measurements}

The measuring instrument consisted of two main sections. The first section collected demographical information of participants, whilst the second section collected opinions of diversity climate.

The diversity climate variable was assessed with the diversity climate instrument developed by McKay et al. (2007). The nine-item scale measures individuals' perceptions of the commitment of the organisation towards eliminating discrimination and creating an environment of inclusivity (McKay et al., 2007). The one-dimensional diversity climate instrument makes use of a 5-point Likert scale, ranging from 1 (well below expectations) to 5 (well above expectations). An
TABLE 2: Sample demographical and biographical information.

\begin{tabular}{lc}
\hline Biographical element & $\%$ \\
\hline Date of birth & \\
1945-1950 & 2.0 \\
1951-1960 & 4.4 \\
1961-1970 & 17.4 \\
1971-1980 & 18.4 \\
1981-1990 & 38.1 \\
1991 and onwards & 19.7 \\
Gender & \\
Male & 46.3 \\
Female & 53.7 \\
Qualifications & \\
Matric/Grade 12 & 22.5 \\
Post-matric qualification (diploma) & 17.9 \\
University degree (BA, BCom, BSc, etc.) & 25.7 \\
Postgraduate degree & 33.9 \\
Demographic/Ethnic group & \\
White people & 64.2 \\
Black people & 31.9 \\
Indian & 1.5 \\
Mixed race & 1.5 \\
Other & 0.9 \\
Employment status & \\
Permanent & 79.3 \\
Temporary & 20.7 \\
Sevel of employment & \\
Middle management & 42.6 \\
General worker & 45.7 \\
\hline & \\
\hline
\end{tabular}

example of an item is 'Workgroup has climate that values diverse perspectives'. According to McKay et al. (2007), the one-dimensional diversity climate assessment previously demonstrated sufficient internal consistency ( $\alpha=0.91$ ).

\section{Statistical analysis}

Data were cleaned, captured and analysed using Statistical Package for Social Sciences (SPSS) and Analysis of a Moment Structure (AMOS) version 26 (IBM Corp., 2019). We calculated descriptive statistics, which included means and standard deviations. To examine the distribution of the data, we calculated skewness and kurtosis scores. According to West, Finch and Curran (1995), cut-off criteria should be 2.00 and 7.00, respectively, whereas Field (2013) suggested that skewness and kurtosis values should be less than 3.29. In terms of reliability, we calculated Cronbach's alpha and inter-item correlations. The minimum acceptable criterion for Cronbach's alphas was set at $\alpha=0.70$, although values of $\alpha>0.80$ are preferable (Pallant, 2013). Mean inter-item correlations ranging from $r=0.15$ to 0.55 were considered adequate (Clark \& Watson, 1995).

To the best of our knowledge, the diversity climate measurement of McKay et al. (2007) has not been subjected to a validation study in South Africa. Consequently, our first statistical step was to examine sampling adequacy. The confirmation of sampling adequacy is an indication that the sample could yield distinctive factors when it is subjected to a factor analysis (Field, 2013). To confirm sampling adequacy, 
a principal component analysis was performed. According to Field (2013), the Kaiser-Meyer-Olkin (KMO) value and Bartlett's test of sphericity can be calculated to determine sampling adequacy. The KMO value should preferably be more than 0.85 and Bartlett's test of sphericity should be significant $(p<0.01)$ (Field, 2013).

Once sampling adequacy was determined, the next step in the analysis consisted of a confirmatory factor analysis (CFA) to determine convergent and discriminant validity. For this purpose, three independent models were constructed in AMOS. The first model considered the total sample group, whilst the second model was constructed by using the data from the white sample group and the final model consisted of the African sample group. The purpose of the CFA was to confirm the diversity climate variable structure for all samples and not to compare models. Following the recommendation of Sun (2005) on construct validity when conducting a CFA, we considered the root mean square error of approximation (RMSEA) as an absolute fit index. In addition, the relative chi-square $\left(\chi^{2} / d f\right)$ (Wheaton, Muthen, Alwin, \& Summers, 1977) was also considered as an absolute fit index. Incremental fit indices included the Tucker-Lewis Index (TLI) and comparative fit index (CFI). The following cut-off criteria were used: RMSEA $<0.08$ (Van de Schoot, Lugtig, \& Hox, 2012), $\chi^{2} / d f<2.0$ (Tabachnick \& Fidell, 2012), CFI and TLI $>0.90$ (Wang \& Wang, 2012). The $\chi^{2}$-statistic was not considered as an absolute fit index as the $\chi^{2}$-statistic was shown to be problematic and sensitive to sample size (Vandenberg \& Lance, 2000).

Examining measurement invariance of an instrument is especially important when planning to compare observations across groups such as in a South African context (Steyn \& De Bruin, 2020). According to Van de Schoot, Schmidt, De Beuckelaer, Lek and Zondervan-Zwijnenburg (2015, p. 1), if researchers wish to compare observations, the survey items should be 'stable'; also known as 'invariant'. Measurement invariance is tested during the CFA process (Van de Schoot et al., 2015). The process as recommended by Vandenberg and Lance (2000) and Cieciuch and Davidov (2016) was used to examine measurement invariance. Based on the recommendation of Cieciuch and Davidov (2016), we compared a configured model against models with increasingly strict equality constraints across the white and African sample groups. The more constrained models included metric invariance model (factor loading equal across groups), scalar invariance (constrained intercepts equal across groups) and partial scalar invariance. For this purpose, we examined the changes in CFI $(\Delta C F I)$ and RMSEA ( $\triangle$ RMSEA) across the white and African sample groups. The $\triangle$ RMSEA should not exceed 0.015 (Chen, 2007), whilst the $\triangle$ CFI should not exceed -0.01 (Cheung \& Rensvold, 2002).

A supplementary validation examination was also performed. For this purpose, an item-total correlation was conducted to assess convergent validity (construct validity). The aim of the item-total correlation was to determine how each item correlates with the scale total. The item-total correlation should be preferably above $r=0.30$ (Pallant, 2013). Item-total correlations were considered significant at $p<0.01$.

\section{Ethical considerations}

This study did not require personal information from respondents and was completely anonymous. Participation in this study was entirely voluntary. The Business School of the North-West University granted ethical clearance for the study (EMSPBS09/09/16-01/01).

\section{Results}

Firstly, we report on findings related to sampling adequacy. Secondly, we report on findings pertaining to CFA. In the third section, we report on descriptive, reliability, kurtosis and skewness statistics. In the final section, we report on results obtained from the item-total correlation calculations.

\section{Reliabilities and descriptive results}

Table 3 shows the results obtained from reliability and descriptive calculations. The reliability results obtained for the total sample group indicated that the data could be considered reliable ( $\alpha=0.91$ and $r=0.54$ ), similarly for the white sample group $(\alpha=0.91$ and $r=0.53)$ and for the African sample group $(\alpha=0.92$ and $r=0.56)$. The central tendencies (means and standard deviations) for all three sample groups were within the scale's positive range, which was an indication that respondents considered their respective organisations as managing and valuing diversity effectively. All skewness and kurtosis scores were less than 3.29 and therefore, the data were normally distributed.

In addition, Cronbach's alphas were also computed for all three sample groups, whilst a specific item was deleted. None of the deleted items improved the reliability score to be more than total Cronbach's alpha score for the sample. This result indicated that it was not necessary to eliminate any item from the diversity climate measuring instrument to improve the overall reliability score.

\section{Sampling adequacy}

The calculation of KMO scores and Bartlett's test of sphericity revealed a significant result. The KMO for the total sample $(n=324)$ was 0.91 and Bartlett's test of sphericity was significant $(p<0.01)$. The white sample

TABLE 3: Reliability and descriptive results.

\begin{tabular}{lcccccc}
\hline $\begin{array}{l}\text { Sample 1 } \\
(\boldsymbol{n}=\mathbf{3 2 3})\end{array}$ & $\begin{array}{c}\text { Cronbach's } \\
\text { alpha }\end{array}$ & $\begin{array}{c}\text { Inter-item } \\
\text { correlations }\end{array}$ & Mean & $\begin{array}{c}\text { Standard } \\
\text { deviation }\end{array}$ & Skewness & Kurtosis \\
\hline $\begin{array}{l}\text { Total sample } \\
\text { group }(n=323)\end{array}$ & 0.91 & 0.54 & 3.41 & 0.76 & -0.46 & 0.16 \\
$\begin{array}{l}\text { White sample } \\
\text { group }(n=208)\end{array}$ & 0.91 & 0.53 & 3.44 & 0.84 & -0.38 & 0.22 \\
$\begin{array}{l}\text { African sample } \\
\text { group }(n=115)\end{array}$ & 0.92 & 0.56 & 3.35 & 0.84 & -0.38 & 0.23 \\
\hline
\end{tabular}


TABLE 4: Fit statistics for confirmatory factor analysis models.

\begin{tabular}{lcccc}
\hline Model (sample) & RMSEA & $\chi^{2} / d f$ & CFI & TLI \\
\hline Total sample group $(n=323)$ & 0.05 & 1.68 & 0.99 & 0.98 \\
White sample group $(n=208)$ & 0.05 & 1.43 & 0.99 & 0.98 \\
African sample group $(n=115)$ & 0.06 & 1.42 & 0.97 & 0.98 \\
\hline
\end{tabular}

$\chi^{2} / d f$, relative/normed chi-square; RMSEA, root mean square error of approximation; $\mathrm{CFI}$ comparative fit index; TLI, Tucker-Lewis Indexm.

group ( $n=208)$ recorded a KMO of 0.89 with a significant Bartlett's test of sphericity score $(p<0.01)$; similarly for the African sample group $(n=115)$, the results indicated a $\mathrm{KMO}$ of 0.89 and a significant Bartlett's test of sphericity $(p<0.01)$. Taking into consideration the results obtained from the sampling adequacy calculations, the total sample group, white sample group and African sample group were all considered adequate for confirmatory factor analysis (CFA).

\section{Confirmatory factor analysis}

The fit statistics for each of the three samples are depicted in Table 4. According to the results in Table 4, the total sample group $(n=323)$ met the minimum CFA fit criteria (RMSEA $\left.=0.05 ; \chi^{2} / d f=1.68 ; \mathrm{CFI}=0.99 ; \mathrm{TLI}=0.98\right)$. The results for the white sample group $(n=208)$ also demonstrated adequate fit $\left(\mathrm{RMSEA}=0.05 ; \chi^{2} / d f=1.43 ; \mathrm{CFI}=0.99 ; \mathrm{TLI}=0.98\right)$, whilst the African sample group similarly met the CFA cut-off criteria $\left(\mathrm{RMSEA}=0.06 ; \chi^{2} / d f=1.42 ; \mathrm{CFI}=0.97 ; \mathrm{TLI}=0.98\right.$ ). The results for the CFA as shown in Table 4 therefore demonstrate adequate construct validity for the diversity climate measurement of McKay et al. (2007) for the total sample group, white sample group and African sample group.

\section{Measurement invariance}

The results obtained for the measurement invariance calculations are presented in Table 5. According to the results in Table 5, the configural invariance model (unconstrained) demonstrated the best fit $\left(\chi^{2} / \mathrm{df}=1.623\right.$; RMSEA $=0.044$; TLI $=0.974 ; \mathrm{CFI}=0.989)$. The remaining measurement invariance models also met the minimum fit criteria. The $\triangle \mathrm{CFI}$ did not exceed -0.01 and the $\triangle$ RMSEA did not exceed 0.15 when comparing the configural model with the more constrained models. The results therefore indicated that the white and African respondents viewed the items of the one-dimensional diversity climate measurement equally.

\section{Item-total correlations}

For the final step, as a supplementary validation (convergent validity), we conducted an item-total correlation analysis. The item-total correlation results are depicted in Table 6 . According to the results, all item-total correlations had a significant relationship with the total scale score $(p<0.01)$. Item-total correlations ranged from $r=0.50$ to $r=0.72$ with all correlations exceeding the minimum threshold of $r=0.30$, as suggested by Pallant (2013). The results in Table 6 confirm that convergent validity was present for the total sample group.
TABLE 5: Measurement invariance for diversity climate measurement.

\begin{tabular}{|c|c|c|c|c|c|c|c|c|}
\hline $\begin{array}{l}\text { Measurement } \\
\text { invariance (MI) } \\
\text { model }\end{array}$ & $\chi^{2}$ & $d f$ & $\chi^{2} / d f$ & RMSEA & TLI & CFI & $\Delta \mathrm{CFI}$ & $\triangle$ RMSEA \\
\hline $\begin{array}{l}\text { Configural } \\
\text { invariance }\end{array}$ & 48.680 & 30 & 1.623 & 0.044 & 0.974 & 0.989 & - & - \\
\hline Metric invariance & 70.800 & 38 & 1.863 & 0.052 & 0.963 & 0.981 & -0.008 & 0.008 \\
\hline Scalar invariance & 95.369 & 47 & 2.029 & 0.057 & 0.956 & 0.972 & -0.009 & 0.005 \\
\hline $\begin{array}{l}\text { Partial scalar } \\
\text { invariance }\end{array}$ & 99.542 & 48 & 2.074 & 0.058 & 0.954 & 0.970 & -0.002 & 0.001 \\
\hline
\end{tabular}

TABLE 6: Item-total correlations.

\begin{tabular}{lcccccccccc}
\hline Item & $\mathbf{1}$ & $\mathbf{2}$ & $\mathbf{3}$ & $\mathbf{4}$ & $\mathbf{5}$ & $\mathbf{6}$ & $\mathbf{7}$ & $\mathbf{8}$ & $\mathbf{9}$ & $\mathbf{D C}$ \\
\hline 1 & 1 & - & - & - & - & - & - & - & - & - \\
2 & $0.53 *$ & 1 & - & - & - & - & - & - & - & - \\
3 & $0.47 *$ & $0.52 *$ & 1 & - & - & - & - & - & - & - \\
4 & $0.52 *$ & $0.56 *$ & $0.57 *$ & 1 & - & - & - & - & - & - \\
5 & $0.50 *$ & $0.62 *$ & $0.48 *$ & $0.67 *$ & 1 & - & - & - & - & - \\
6 & $0.50 *$ & $0.60 *$ & $0.46 *$ & $0.51 *$ & $0.54 *$ & 1 & - & - & - & - \\
7 & $0.47 *$ & $0.51 *$ & $0.48 *$ & $0.51 *$ & $0.49 *$ & $0.70 *$ & 1 & - & - & - \\
8 & $0.53 *$ & $0.55 *$ & $0.51 *$ & $0.61 *$ & $0.53 *$ & $0.72 *$ & $0.72 *$ & 1 & - & - \\
9 & $0.46 *$ & $0.39 *$ & $0.56 *$ & $0.49 *$ & $0.46 *$ & $0.46 *$ & $0.56 *$ & $0.63 *$ & 1 & - \\
DC & $0.72 *$ & $0.77 *$ & $0.73 *$ & $0.79 *$ & $0.77 *$ & $0.79 *$ & $0.78 *$ & $0.83 *$ & $0.73 *$ & 1 \\
\hline
\end{tabular}

*Note: Significance was considered at $p<0.01$.

DC, Diversity climate.

\section{Discussion}

It is apparent from the literature that validation and measurement invariance is an important step in South African organisational behaviour research, especially when aiming to compare observations across groups. This is mainly because of the wide range of diverse cultures within South African organisations. Furthermore, there seems to be a significant research gap within the diversity climate literature pertaining to conceptualisations and validations of diversity climate assessments especially across race groups (CachatRosset et al., 2019; Mckay \& Avery, 2015; Perry, Li, Perry, \& $\mathrm{Li}, 2019)$. A majority of studies have focused on gender (Holmes et al., 2020; Paolillo et al., 2017) and therefore, the present study contributes to the diversity climate body of knowledge with an examination across race groups in a nonwestern sample. Consequently, the present study was aimed at conceptualising diversity climate for the South African milieu, sourcing and identifying a relevant diversity climate assessment and finally examining the psychometric properties of the identified diversity climate instrument.

Diversity-related legislation is an important platform for diversity management and diversity climate is a representation of how diversity is managed. An analysis of diversity-related South African legislation demonstrates that diversity climate as a concept within a South African diversity environment should include perspectives on appreciation of diversity, well-formulated diversity-related policies and procedures and a stimulated process of diversification. Consequently, we propose that diversity climate for the South African environment should be considered as representing employee perceptions of how well the organisation is able to create openness and an appreciation of 
diversity through its formulated diversity managementrelated policies, practices and procedures, including the stimulation of a diversification process. An examination of diversity climate instruments revealed that the onedimensional instrument of McKay et al. (2007) could be suitable for the South African environment.

The next phase of this study was to validate the selected diversity climate assessment instrument. The CFA that followed confirmed the one-dimensional structure for the total sample group $(n=324)$, African sample group $(n=115)$ and white sample group $(n=208)$ and therefore confirmed the original findings by McKay et al. (2007).

However, within a diverse environment such as South Africa, construct validation is not sufficient evidence for future crosscultural studies. Consequently, measurement invariance in a South African environment was assessed as proposed by Steyn and De Bruin (2020). Results from the measurement invariance computations indicated that the configural model, which included the African and white sample groups, met the fit criteria as recommended in the literature. The configural model further held firm against the more constrained models, confirming that African and white respondents viewed the onedimensional diversity climate assessment instrument similarly.

\section{Practical and theoretical implications}

The literature suggests that diversity climate can be considered as an indication of how well an organisation is managing diversity. Therefore, organisations which wish to examine and evaluate their efforts in managing their diverse workforces may apply the one-dimensional diversity climate assessment of McKay et al. (2007), especially if they wish to compare observations across ethnic groups. Organisations which wish to design new or amended diversity-related interventions should commence with an assessment of the current situation (Mor Barak, 2015). For an assessment of the current situation regarding diversity management efforts and interventions, organisations and practitioners will require a validated instrument, especially for a culturally diverse environment such as South Africa. The present study therefore contributes to the essential practice of diversity management practitioners by providing evidence of a validated diversity climate measuring instrument.

In terms of theoretical contributions, the present study endeavours to provide South African diversity management researchers with a validated platform on which they can contribute to diversity climate literature. South Africa remains a unique and diverse environment that provides a fascinating diversity management milieu within which to conduct research. Therefore, the present examination not only contributes to South African diversity management literature but also addresses concerns and improvement opportunities raised by international diversity climate scholars (Cachat-Rosset et al., 2019; Holmes et al., 2020; Mckay \& Avery, 2015; Perry et al., 2019).

\section{Limitations and recommendations for future research}

Although cross-sectional studies are valuable to assess observations at a single point in time (Spector, 2019), the present study had a limitation as the measurement invariance assessment was restricted only to the white and African sample groups. A future study should attempt to obtain sufficient data to also include other ethnic groups.

Although several previous studies have examined the gender diversity climate perspectives (Holmes et al., 2020; Mor Barak et al., 1998), a South African view would not only advance diversity climate studies but also contribute to intersectional knowledge of the South African workforce (Rodriguez, Holvino, Fletcher, \& Nkomo, 2016). Future studies could also be extended to gender groups or any other differentiating dimension, which is considered important in the South African diversity management context.

A closer inspection of the one-dimensional instrument does not reveal any causes that might have produced common method bias as proposed by MacKenzie and Podsakoff (2012). However, as with any survey, common method bias will remain a concern. We recommend that future studies should also conduct a Harman's single-factor test, especially if diversity climate is assessed using other variables and to also implement the correlation matrix procedure (RodríguezArdura \& Meseguer-Artola, 2020).

The collection of data was restricted to organisations in the Gauteng province. Future studies should include organisations from other economic areas in South Africa.

\section{Conclusion}

This article identified research opportunities within the diversity climate literature pertaining to conceptualisations, validation and measurement invariance. The one-dimensional diversity climate measurement of McKay et al. (2007) passed a set of rigorous validation assessments using a South African data set and was demonstrated to be a valid measurement instrument for white and African respondents.

\section{Acknowledgements Competing interests}

The authors declare that they have no financial or personal relationships that may have inappropriately influenced them in writing this article.

\section{Authors' contributions}

S.M. and M.M.H. contributed equally to this article.

\section{Funding information}

This research received no specific grant from any funding agency in the public, commercial or not-for-profit sectors. 


\section{Data availability}

The authors confirm that the data supporting the findings of this study are available within the article.

\section{Disclaimer}

The views and opinions expressed in this article are those of the authors and do not necessarily reflect the official policy or position of any affiliated agency of the authors.

\section{References}

Cachat-Rosset, G., Carillo, K., \& Klarsfeld, A. (2019). Reconstructing the concept of diversity climate - A critical review of its definition, dimensions, and operationalization. European Management Review, 16(4), 863-885. https://doi. org/10.1111/emre.12133

Chen, F.F. (2007). Sensitivity of goodness of fit indexes to lack of measurement invariance. Structural Equation Modeling, 14(3), 464-504. https://doi. org/10.1080/10705510701301834

Cheung, G.W., \& Rensvold, R.B. (2002). Evaluating goodness-of-fit indexes for testing measurement invariance. Structural Equation Modeling, 9(2), 233-255. https:// doi.org/10.1207/S15328007SEM0902_5

Cieciuch, J., \& Davidov, E. (2016). Establishing measurement invariance across online and offline samples: A tutorial with software packages AMOS and Mplus. Studia Psychologica, 14(15/2), 83. https://doi.org/10.21697/sp.2015.14.2.06

Clark, L.A., \& Watson, D. (1995). Constructing validity: Basic issues in objective scale development. Psychological Assessment, 7(3), 309-319. https://doi.org/10.1037/ 1040-3590.7.3.309

Cox, T. (1994). Cultural diversity in organisations: Research, theory and practice. Journal of Intercultural Management, 2(2), 5-15. Retrieved fom http://joim.pl/ pdf/MAZURv2n2.pdf

Cox, T.J. (1993). Cultural diversity in organizations: Theory, research, and practice. International Journal of Organizational Analysis. Berrett-Koehler. Retrieved fom https://books.google.co.jp/books?hl=en\&lr=\&id=Dr7|l|PVGJYC\&oi=fnd\&pg=PT1\& $\mathrm{dq}=$ definition+of+cultural+diversity+in+the+workplace \&ots=g2 wbUli531\&sig= WTuQcDzbPvlHe12p4TPEAMQpNns\&redir_esc=y\#v=onepage \& $q=$ definition of cultural diversity in the workplace \&f=false

Field, A. (2013). Discovering statistics using IBM SPSS statistics. Statistics. London: SAGE Publications.

Heyns, M., \& Ellis, S.M. (2013). Validation of a trustworthiness questionnaire for South African workplace context. In 7th International Business Conference, n.d. Seychelles: s.l.

Hofhuis, J., Van der Zee, K.I., \& Otten, S. (2012). Social identity patterns in culturally diverse organizations: The role of diversity climate. Journal of Applied Social Psychology, 42(4), 964-989. https://doi.org/10.1111/j.1559-1816.2011.00848.x

Holmes, O., Jiang, K., Avery, D.R., McKay, P.F., Oh, I.S., \& Tillman, C.J. (2020). A metaanalysis integrating 25 years of diversity climate research. Journal of Management, 1-26. https://doi.org/10.1177/0149206320934547

IBM Corp. (2019). IBM SPSS statistics for Windows, Version 26.0. Armonk, NY: IBM Corp.

Jackson, S.E., Brett, J.F., Sessa, V.I., Cooper, D.M., Julin, J.A., \& Peyronnin, K. (1991) Some differences make a difference: Individual dissimilarity and group heterogeneity as correlates of recruitment, promotions, and turnover. Journal of heterogeneity as correlates of recruitment, promotions, and turn
Applied Psychology. https://doi.org/10.1037/0021-9010.76.5.675

Jackson, L.T.B., \& Van de Vijver, F.J.R. (2018). Multiculturalism in the workplace: Mode and test. SA Journal of Human Resource Management, 16(2), a908. https://doi. arg/10.4102/sajhrm.v16i0.908

Leslie, L.M. (2017). A status-based multilevel model of ethnic diversity and work unit performance. Journal of Management, 76(5), 675-689. https://doi. org/10.1177/0149206314535436

Luu, T.T. (2019). Can diversity climate shape service innovative behavior in Vietnamese and Brazilian tour companies? The role of work passion. Tourism Management 72, 326-339. https://doi.org/10.1016/j.tourman.2018.12.011

MacKenzie, S.B., \& Podsakoff, P.M. (2012). Common method bias in marketing: Causes, mechanisms, and procedural remedies. Journal of Retailing, 88(4), 542-555. https://doi.org/10.1016/j.jretai.2012.08.001

McCallaghan, S., Jackson, L., \& Heyns, M. (2019). Exploring organisational diversity climate with associated antecedents and employee outcomes. SA Journal of Industrial Psychology, 45(1), a1614. https://doi.org/10.4102/sajip.v45i0.1614

McKay, P.F., \& Avery, D.R. (2015). Diversity climate in organizations: Current wisdom and domains of uncertainty. Research in Personnel and Human Resources Management, 33, 191-233. https://doi.org/10.1108/S0742-730120150000033008

McKay, P.F., Avery, D.R., \& Morris, M.A. (2008). Mean racial-ethnic differences in employee sales performance: The moderating role of diversity climate. Personne Psychology, 61(2), 349-374. https://doi.org/10.1111/j.1744-6570.2008.00116.x
McKay, P.F., Avery, D.R., Tonidandel, S., Morris, M.A., Hernandez, M., \& Hebl, M.R. (2007). Racial differences in employee retention: Are diversity climate perceptions the key? Personnel Psychology, 60(1), 35-62. https://doi.org/10.1111/ perceptions the key? Perso

Mor Barak, M.E. (2015). Inclusion is the key to diversity management, but what is inclusion? Human Service Organizations Management, Leadership and Governance, 39(2), 83-88. https://doi.org/10.1080/23303131.2015.1035599

Mor Barak, M.E., Cherin, D.A., \& Berkman, S. (1998). Organizational and personal dimensions in diversity climate: Ethnic and gender differences in employee perceptions. Journal of Applied Behavioral Science, 34(1), 82-104. https://doi. org/10.1177/0021886398341006

Pallant, J. (2013). SPSS survival manual (5th edn.). Berkshire: Open University Press Allen \& Unwin.

Paolillo, A., Pasini, M., Silva, S.A., \& Magnano, P. (2017). Psychometric properties of the Italian adaptation of the Mor Barak et al. diversity climate scale. Quality and Quantity, 51(2), 873-890. https://doi.org/10.1007/s11135-016-0316-3

Perry, E.L., Li, A., Perry, E.L., \& Li, A. (2019). Diversity climate in organizations. In Oxford research encyclopedia of business and management. Retrieved from https:// oxfordre.com/business/view/10.1093/acrefore/9780190224851.001.0001/ acrefore-9780190224851-e-45

Peterson, L. (1999). The definition of diversity: Two views. a more specific definition Journal of Library Administration, 27(1-2), 17-26. https://doi.org/10.1300/ J111v27n01_03

Pugh, S.D., Dietz, J., Brief, A.P., \& Wiley, J.W. (2008). Looking inside and out: The impact of employee and community demographic composition on organizational diversity climate. Journal of Applied Psychology, 93(6), 1422-1428. https://doi. org/10.1037/a0012696

Reinwald, M., Huettermann, H., \& Bruch, H. (2019). Beyond the mean: Understanding firm-level consequences of variability in diversity climate perceptions. Journal of Organizational Behavior, 40(4), 472-491. https://doi.org/10.1002/job.2344

Rodriguez, J.K., Holvino, E., Fletcher, J.K., \& Nkomo, S.M. (2016). The theory and praxis of intersectionality in work and organisations: Where do we go from here? Gender, Work and Organization, 23(3), 201-222. https://doi.org/10.1111/ gwao.12131

Rodríguez-Ardura, I., \& Meseguer-Artola, A. (2020). Editorial: How to prevent, detect and control common method variance in electronic commerce research. Journal of Theoretical and Applied Electronic Commerce Research, 15(2), 1-5. https://doi. org/10.4067/S0718-18762020000200101

Spector, P.E. (2019). Do not cross me: Optimizing the use of cross-sectional designs. Journal of Business and Psychology, 34(2), 125-137. https://doi.org/10.1007/ s10869-018-09613-8

South Africa. (1996). Constitution of South Africa. Pretoria: Government Printers.

South Africa. (1997). Basic Conditions of Employment Act 75 of 1997. Pretoria: Government Printers.

South Africa. (1997). Labour Relations Act 66 of 1995. Pretoria: Government Printers.

South Africa. (1998). Employment Equity Act 55 of 1998. Pretoria: Government Printers.

South Africa. (2003). Broad-Based African Economic Empowerment Act 53 of 2003. Pretoria: Government Printers.

Statistics South Africa. (2020). Quarterly labour force survey, Pretoria: Stats SA.

Steyn, R., \& De Bruin, G.P. (2020). An investigation of gender-based differences in assessment instruments: A test of measurement invariance. SA Journal of Industrial Psychology, 46(4), 1-12. https://doi.org/10.4102/sajip.v46i0.1699

Sun, J. (2005). Assessing goodness of fit in confirmatory factor analysis. Measurement and Evaluation in Counseling and Development, 37(4), 240-256. https://doi. org/10.1080/07481756.2005.11909764

Tabachnick, B.G., \& Fidell, L.S. (2012). Using multivariate statistics (6th edn.). New York, NY: Harper and Row.

Tafjel, H., \& Turner, J.C. (1986). The social identity theory of intergroup behaviour. In S. Worchel \& W.G. Austin (Eds.), Psychology of intergroup relations (2nd edn., p. 724). Chicago, IL: Nelson-Hall.

Van De Schoot, R., Lugtig, P., \& Hox, J. (2012). A checklist for testing measurement invariance. European Journal of Developmental Psychology, 9(4), 486-492. https://doi.org/10.1080/17405629.2012.686740

Van De Schoot, R., Schmidt, P., De Beuckelaer, A., Lek, K., \& Zondervan-Zwijnenburg, M. (2015). Editorial: Measurement invariance. Frontiers in Psychology, 6(883), 1064. https://doi.org/10.3389/fpsyg.2015.01064

Vandenberg, R.J., \& Lance, C.E. (2000). A review and synthesis of the measurement invariance literature: Suggestions, practices, and recommendations for organizational research. Organizational Research Methods, 3(1), 4-70. https:// doi.org/10.1177/109442810031002

Wang, J., \& Wang, X. (2012). Structural equation modelling: Applications using Mplus. Chichester: John Wiley \& Sons. https://doi org/10.1002/9781118356258

West, S.G., Finch, J.F., \& Curran, P.J. (1995). Structural equation models with nonnormal variables: Problems and remedies. In R.H. Hoyle (Ed.), Structural equation modeling: Concepts, issues and applications (pp. 56-75). Newbury Park CA: Sage.

Wheaton, B., Muthen, B., Alwin, D.F., \& Summers, G.F. (1977). Assessing reliability and stability in panel models. Sociological Methodology, 8, 84-136. https://doi. org/10.2307/270754 